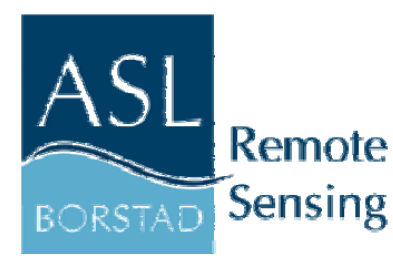

\title{
Examining Change and Long-Term Trends in the Marine Environment Using Satellite-Based Time Series
}

\author{
G. A. Borstad, L. N. Brown and D.B. Fissel \\ ASL Environmental Sciences Inc. \\ 1986 Mills Road, Sidney, BC Canada
}

\begin{abstract}
The oceans and coastal areas are dynamic environments in which variability occurs at a wide range of temporal scales, from seconds to years to decades and longer. Some very good time series now exist at specific locations, that permit characterization of this variability as well as of longer-term trends, but for much of the world ocean the in situ data is sparse and such characterization is not possible, or possible only by extrapolation. For these less well-studied areas, satellite imagery and gridded products created from a combination of satellite and in situ data are the only available sources of continuous historical information. Satellite imagery provides regular, spatially synoptic, global information, at spatial resolutions on the order of $1 \mathbf{k m}$ and temporal resolutions typically measured in days. Some sensors offer higher spatial resolutions but at lower temporal resolution. With accumulated time series of up to 30 years or longer for some satellites and other gridded datasets, we can now begin to use this technology to identify and track long-term change, as well as to characterize shorter-term variability.
\end{abstract}

In this paper we will discuss the analysis of long-term change and trends in marine and coastal environments using examples from recent projects. We will illustrate vegetation changes in and around the Anderson River delta on the Beaufort Sea coast of the Arctic Ocean using 30m spatial resolution Landsat imagery acquired over a 31-year period from 1972 to 2003. Using a temporal classification approach, we map both interannual variability and long-term losses on the mudflats of the delta itself, and gains on the nearby tundra. In a second example, we illustrate how chlorophyll and sea surface temperature (SST) vary locally within the northeast Pacific, and how temporal patterns and trends also vary regionally, using 24 years of weekly $4 \mathbf{k m}$ resolution sea surface temperature from the weather satellites, and 11 years of weekly $9 \mathrm{~km}$ chlorophyll composite data products from ocean colour satellites. Finally, we show examples of trends and anomalies calculated from 41 years of sea ice distribution, concentrations and ice type in the Beaufort Sea, using ice chart maps produced by the Canadian Ice Service from a combination of satellite, airborne and in situ observations. The weekly ice charts provide coverage of the entire western hemisphere of the Arctic Ocean over the continental shelf, slope and rise areas at a spatial resolution of $4 \mathrm{~km}$ for a total of 26 distinct ice parameters spanning the years 1968 to the present. Using this rich data source, the analysis of long-term trends in relation to seasonal and interannual variability can be used to estimate potential changes due to climate change for local and regional areas, which are shown to vary considerably from one region to another.

The availability of data from all of the sources discussed over extended time periods of 30 years or longer provides a means of assessing the potential degree of climate change that has been occurring over the present and earlier decades. This information can also be useful in calibrating and validating models that can be applied to anticipate and quantify the effects of climate change which may occur in future decades.

\section{INTRODUCTION}

Tracking change in remote parts of the globe is a challenge that is increasingly well met by satellite imaging. This is particularly true of the marine environment where change occurs over a wide range of scales, both temporal and spatial. While traditional in situ observations are unavoidably constrained to point or occasionally linear measurements in space (ship transects) or time (moored buoys), satellite imaging offers synoptic coverage on a regular basis, at resolutions on the order of $1 \mathrm{~km}$ and 1 day. Some of the other advantages of remote sensing data are summarized in Table I.

Earth observing satellites have been in operation since the early 1960's. The earliest satellites were designed chiefly for weather applications, but beginning in the 1970's land and ocean observing satellites appeared with the launch of the first of the Landsat series in 1972 and the Coastal Zone Color Scanner (CZCS) in 1978. Passive microwave imaging began in 1972 with Nimbus 5 and the capability of monitoring sea ice. Since then newer generations of sensors have increased the capabilities of these early instruments, with better sensitivity, higher resolution and improved algorithms, as well as expanding the array of earth observation applications.

This now 30-plus year archive of satellite imagery enables users to examine long-term change and variability in the marine environment. In some cases the same sensor or series of sensors (e.g., Landsat, 1972 to present, AVHRR, 1985 to present) have provided continuous or near continuous datasets over their lifetimes, while in other cases different sensors have evolved with improving capabilities to monitor specific parameters (e.g., CZCS, SeaWiFS, MODIS for ocean colour). For these latter in particular, data providers have been careful to address intercalibration issues and to correct for these where possible. Merged datasets now exist for some important parameters such as sea surface temperature (SST) and ocean chlorophyll in an attempt to provide high quality datasets for temporal analysis. 
We present three examples of long-term time series analysis that examine vegetation change in the coastal zone, scales of SST and chlorophyll variability in the northeast Pacific, and the varying effects of seasonal, annual and climate change on ice in the Beaufort Sea.

TABLE I

ADVANTAGES OF THE USE OF SATELLITE IMAGERY AND RELATED GRIDDED PRODUCTS

\begin{tabular}{|l|}
\hline Synoptic, global coverage \\
\hline Remote or inaccessible areas - can be the only practical way of gathering information \\
\hline Access without administrative restrictions across national boundaries \\
\hline Ever lengthening global time series \\
\hline Can be repeated at intervals to provide temporal monitoring and change analysis \\
\hline Varying scales, GIS compatible \\
\hline Many physical and biological variables can be measured and mapped \\
\hline Low cost or free data \\
\hline
\end{tabular}

\section{EXAMPLES OF SATELLITE DERIVED TIME SERIES}

Reduction in Vegetation Cover at the Anderson River Delta, Northwest Territories, Identified by Landsat Imagery, 1972-2003

Qualitative and anecdotal reports from hunters indicate the disappearance of vegetation from the outermost part of the Anderson River delta, Northwest Territories. The delta, part of a federal migratory bird sanctuary, is among the most important areas for breeding and summering birds in the Northwest Territories, and loss or degradation of habitat there is an important conservation issue. Thus, the objectives of this study [1] were to quantify the habitat loss at the Anderson River delta and to determine when the loss occurred.

We mapped changes in vegetation cover of the Anderson River delta for the 31-year period, 1972-2003, using 13 multispectral images gathered by sensors of the American Landsat satellite series. In any time series analysis such as this, it is important to account for variability in the satellite imagery (e.g., differences in sensor types, aging of the sensors, atmospheric effects, and annual differences in weather or growing season) which could influence results. We carefully converted the imagery to top-ofatmosphere reflectance. In an attempt to limit the seasonal effects, we chose images from a limited period each year (30 June to 8 August), matching the peak of summer vegetative growth. Small differences in the "biological" date of the images probably remained after this matching, as the timing of the seasons can vary significantly among years. Therefore, we also considered annual variability in spring weather (June temperatures) when carrying out analyses and evaluating long-term changes in vegetation.

The Normalized Difference Vegetation Index (NDVI), a quantitative index of chlorophyll-containing plant biomass or vegetative cover, was calculated for each image in the time series (Fig. 1). Long-term changes in NDVI were assessed in three ways: (1) by measuring the areal extent of habitat change over the 31-year study period, (2) by estimating the change in mean NDVI over time for several Regions of Interest (ROIs) within the study area, and (3) by creating thematic maps of NDVI change over time using an unsupervised classification approach (Fig. 2).

Results of the three types of analysis showed good agreement. The areal extent of habitat loss in the Outer Islands used by most of the nesting Lesser Snow Geese (Chen caerulescens caerulescens) and Black Brant (Branta bernicla nigricans) was 45\% and the mean NDVI value for the ROI declined by 37.5\%. Reductions in the areal extent of plant cover (ranging from 7\% to 92\%) and NDVI (ranging from 7.9\% to 78.6\%) varied greatly among seven subregions comprising the Outer Islands. In one of these, the Western Delta, the extent of vegetation cover declined by 18\%, and the mean NDVI declined by $11.9 \%$. Visual observations of habitat change indicate that dead shrubs and barren mud flats now occupy significant parts of the delta that were apparently well vegetated by willows, grasses and sedges, and other herbaceous plants in the past (Fig. 1). Soil samples taken from the areas with degraded habitat are highly saline, implicating salt water flooding by the Beaufort Sea as a potential cause of vegetation loss. NDVI values in the Outer Islands and parts of the Western Delta were variable from year to year and we were unable to attribute NDVI change to catastrophic loss of habitat such as might be caused by large storm surges in one or two years. Rather, it appeared that loss in vegetation has been occurring gradually since at least 1972. 


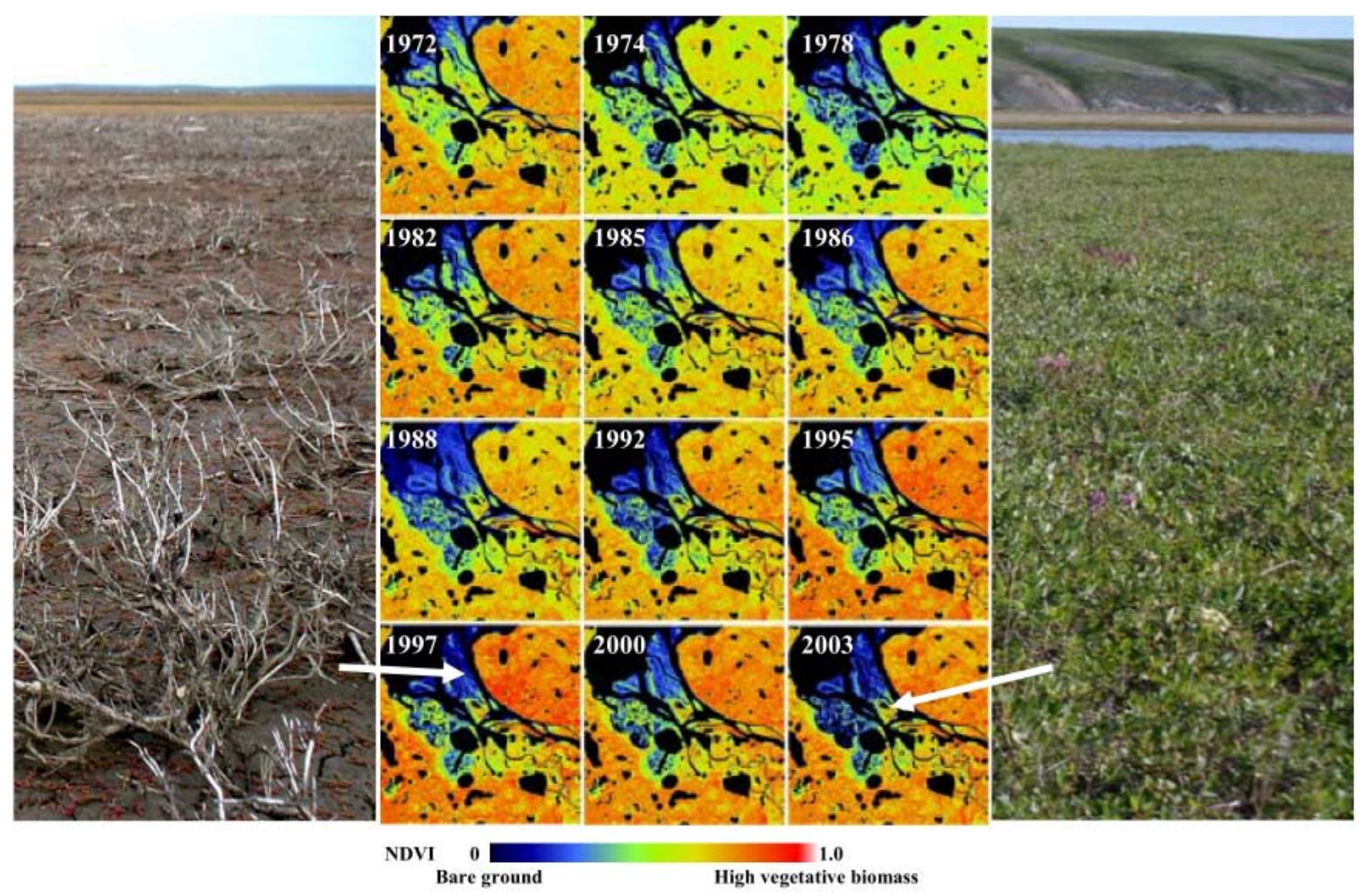

Fig. 1 Normalized Difference Vegetation Index (NDVI) images for the Anderson River delta, 1972-2003. NDVI increases from blue through red to white. Water areas are black. Photo at left illustrates dead vegetation on tidal flats in 2003. Right photo is from an area of lush dwarf shrub vegetation.

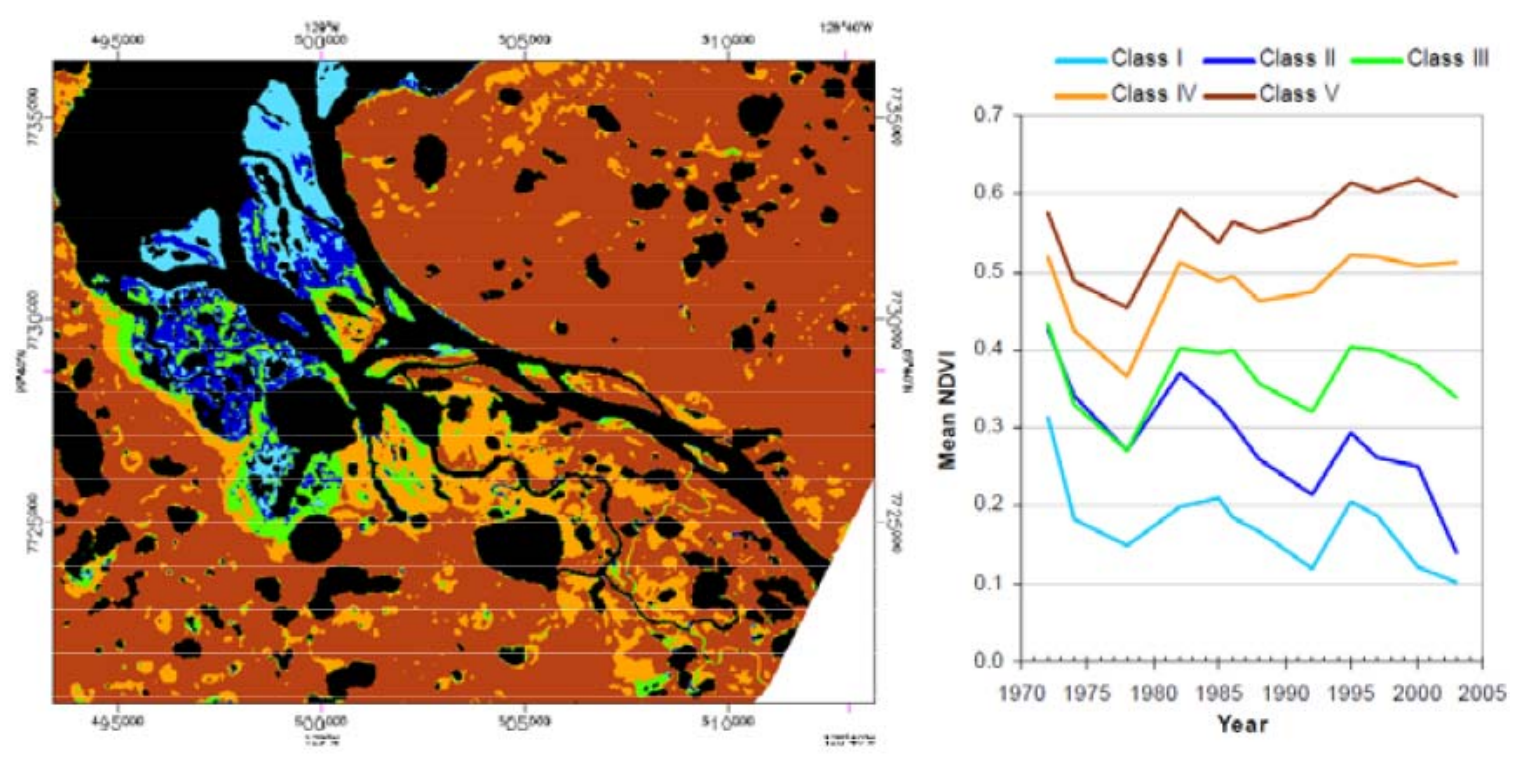

Fig. 2 Five thematic classes of vegetation change over time at the Anderson River Delta Migratory Bird Sanctuary, Northwest Territories, 1972-2003. Statistically significant declining trends in Normalized Difference Vegetation Indices (NDVI) were noted for lowland Classes I and II, and a positive trend was observed for upland tundra (Class V). 
In contrast to the situation in the outer delta, where vegetation loss was prevalent, our analyses showed that the NDVI values for upland tundra near the Anderson River delta increased by 21.1\% between 1972 and 2003. There was also a significant correlation between NDVI and spring temperature for the uplands area. These findings were in agreement with other studies carried out since the 1980s in Siberia [2] and Alaska [3] that used Advanced Very High Resolution Radiometer (AVHRR) data to describe a 25-year period of more or less constant increase in NDVI. However, our longer time series showed a period of considerable interannual variations in NDVI and both high and low NDVI values early in our time series that were apparently driven by relatively warm $(1972,1982)$ and cool $(1974,1978)$ spring weather, respectively. The significant positive relationship between uplands NDVI and year no longer existed when the influence of June weather (mean daily temperature) was "controlled for" statistically.

\section{The Northeast Pacific Ocean}

The west coast of North America is an oceanographically complex area, dominated by the downwelling Alaska Current regime in the north, the upwelling California Current regime in the south, and transitional waters off southern British Columbia. There is a strong seasonality to the upwelling/downwelling conditions, with a summer northward shift of the Alaska Current regime that results in increased upwelling off British Columbia and concomitant effects on nutrient availability and primary productivity. The region is also subject to significant freshwater inflow, as well as episodic events such as El Nino and decadal cycles such as the Pacific Decadal Oscillation (PDO).

We used satellite observations of sea surface temperature (SST) from AVHRR Pathfinder and chlorophyll from SeaWiFS to capture this spatial and temporal variability, by dividing the region into 14 oceanographic zones described by [4] (Fig. 3), and extracting the 24-year time series of SST and 11-year series of chlorophyll for each zone. Fig. 4 compares the average annual cycles for the 14 zones, arranged roughly northwest to southeast. Although the generalized SST patterns are similar among the Alaska Current dominated zones, there is considerable regional variation of both timing and magnitude in the chlorophyll cycles, some zones exhibiting two equal or nearly equal growth periods in spring and fall, others characterized by one dominant annual bloom in either spring or fall. The Strait of Georgia/Johnstone Strait zone is noticeably productive, with two to three times the average standing stock of chlorophyll in other zones. This oceanographically distinct area lies between Vancouver Island and the mainland, and as such is removed from some of the outer coast influences but strongly affected by outflow from the Fraser River.

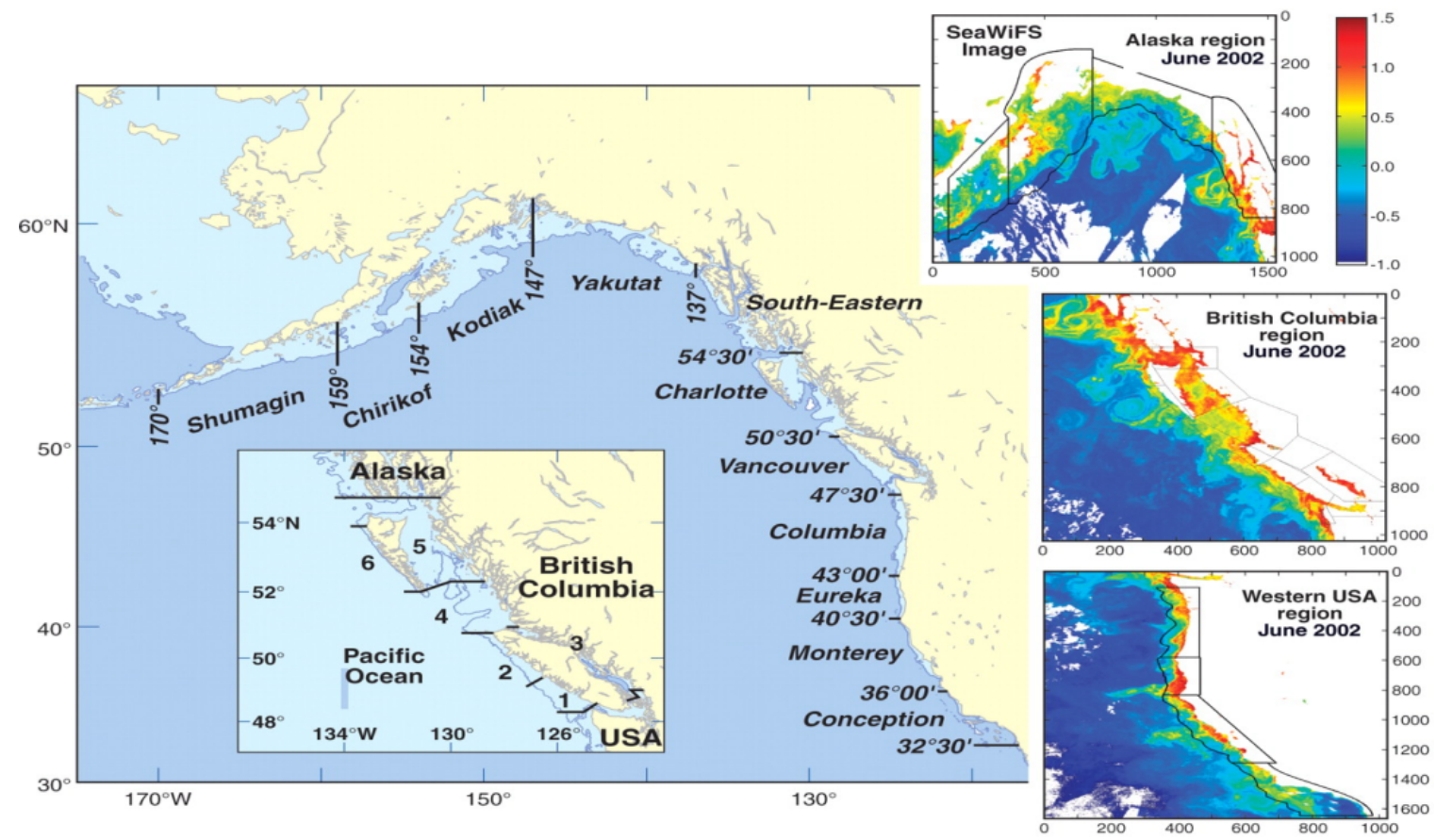

Fig. 3 Coastal oceanographic zones of the northeast Pacific defined by [4] (small figures), based on statistical fishing areas used by the North Pacific Anadromous Fish Commission (large figure). 
Fig. 5 compares the generalized chlorophyll cycles with SeaWiFS observed chlorophyll for the years 1998 to 2008, for the open west coast of Vancouver Island (BC zones 1 and 2) and the Strait of Georgia/Johnstone Strait system (BC zone 3). Interannual variability is evident in both regions, but the same trends are not necessarily observed at the same time in the two systems. The years 2007 and 2008 were unusually productive in both, and also lacked the characteristic spring/fall seasonality normally associated with these zones. In contrast, the year 2005 was a poor chlorophyll year on the west coast, with very low spring production and lower than average fall production; in the Straits, the same year exhibited a strong, early spring bloom but low fall chlorophyll levels. Evidence of higher order effects were seen up the food chain: 2005 was considered to be a bad year for west coast salmonids, but Georgia Strait salmonids entering the sea early in the spring performed well [5].

With a 24-year archive, satellite SST extends far enough back in time to begin to show decadal scale variability, including trends related to ocean indices like the Pacific Decadal Oscillation and the Ocean Nino Index (Fig. 6). The 1997-98 El Nino event shows clearly in the West Coast SST anomaly, as do the alternate cooling (1999-2002, 2008) and warming (2003-06) phases of the PDO.

For temporal and regional analyses such as these, satellite data holds tremendous advantage over in situ oceanographic measurements made from ships or moored buoys which can offer at best point or transect data and can miss spatially localized or transient events. As the archive grows, satellite time series will become increasingly useful for tracking longer-term effects such as climate change.

SST

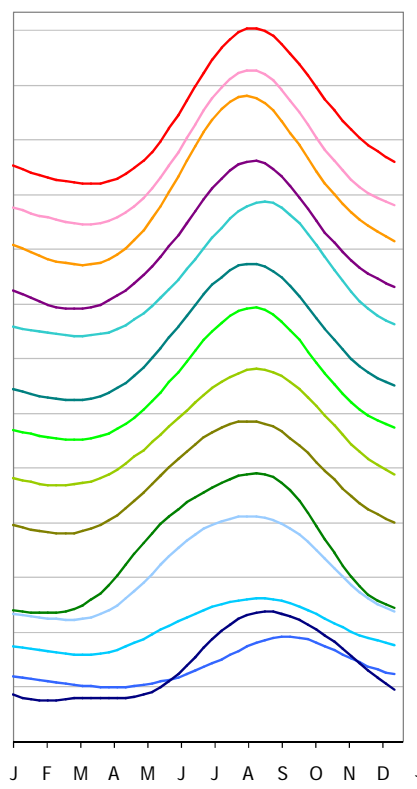

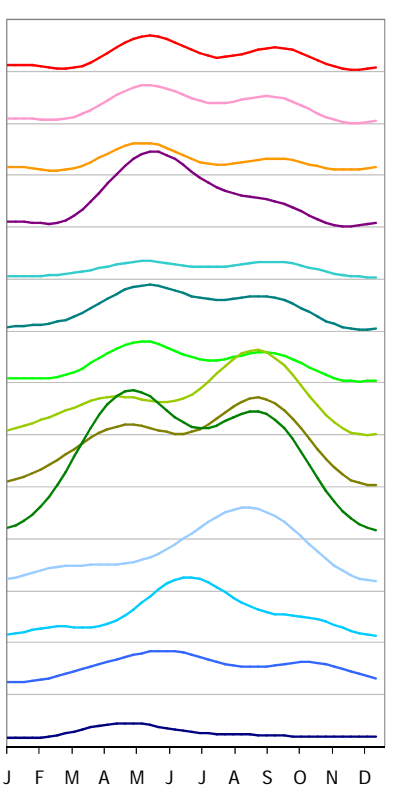

-AK 1 Chirikof

- AK 2 Kodiak

- AK 3 Yakutat

-AK 4 Southeastern

— BC-6 Outer Queen Charlotte Islands

—BC-5 Hecate Strait/Dixon Entrance

- BC-4 Queen Charlotte Sound

- BC-2 NW coast Vancouver Island

- BC-1 SW coast Vancouver Island

-BC-3 Georgia Strait/J ohnstone Strait

—US 1 Columbia

—US 2 Eureka

—US 3 Monterey

-US 4 Conception

Fig. 4 Annual canonical cycles of satellite SST and chlorophyll for 14 oceanographic zones along the west coast of North America, arranged approximately northwest to southeast. SST plots are offset $3^{\circ}$ per zone, chlorophyll $4 \mathrm{mg} \mathrm{m}^{-3}$ per zone.

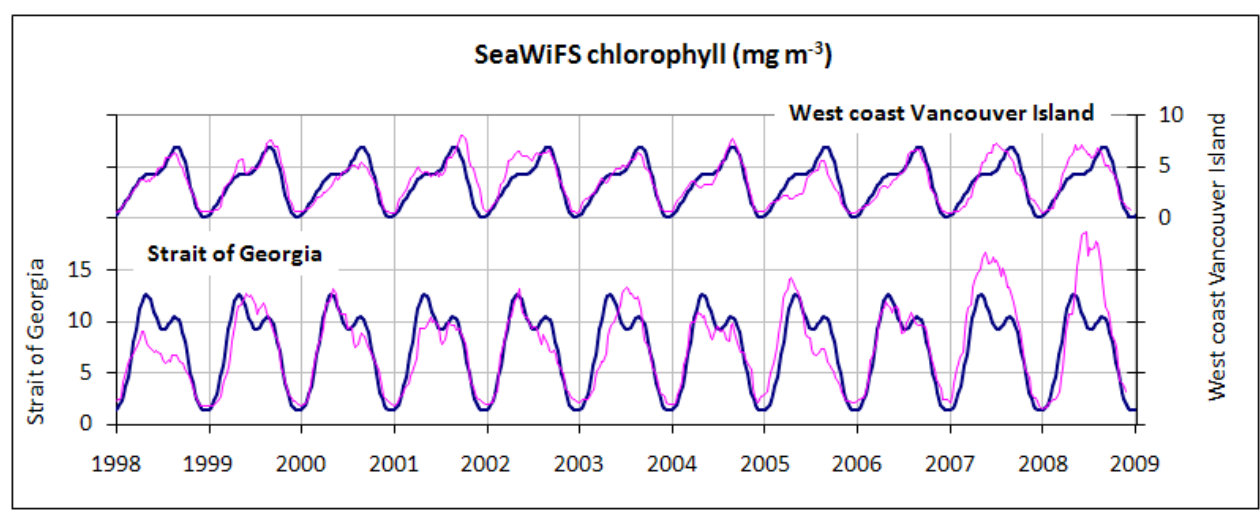

Fig. 5 Average annual chlorophyll cycle (blue) and SeaWiFS observed chlorophyll (mg $\mathrm{m}^{-3}$, magenta) for the west coast of Vancouver Island and the Strait of Georgia. 
A

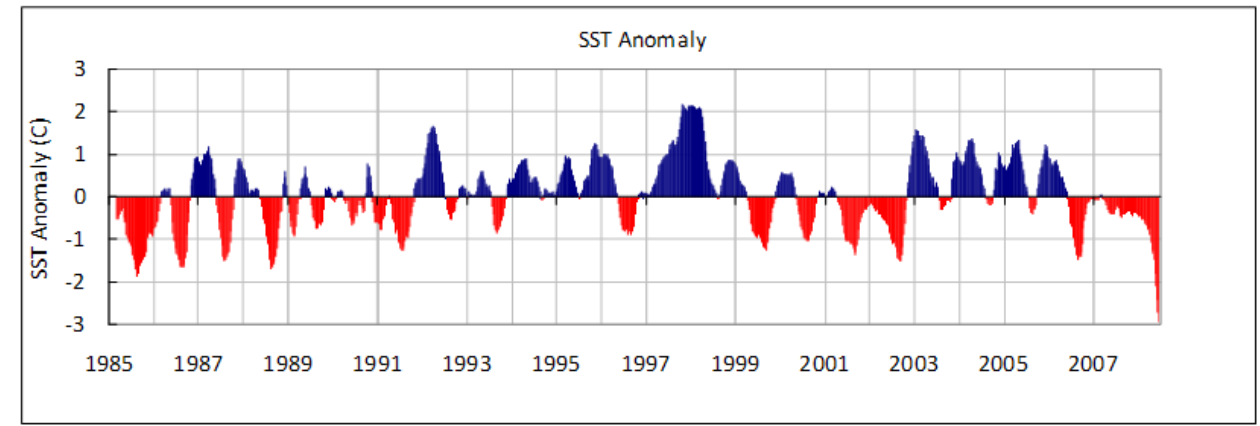

$\mathrm{B}$

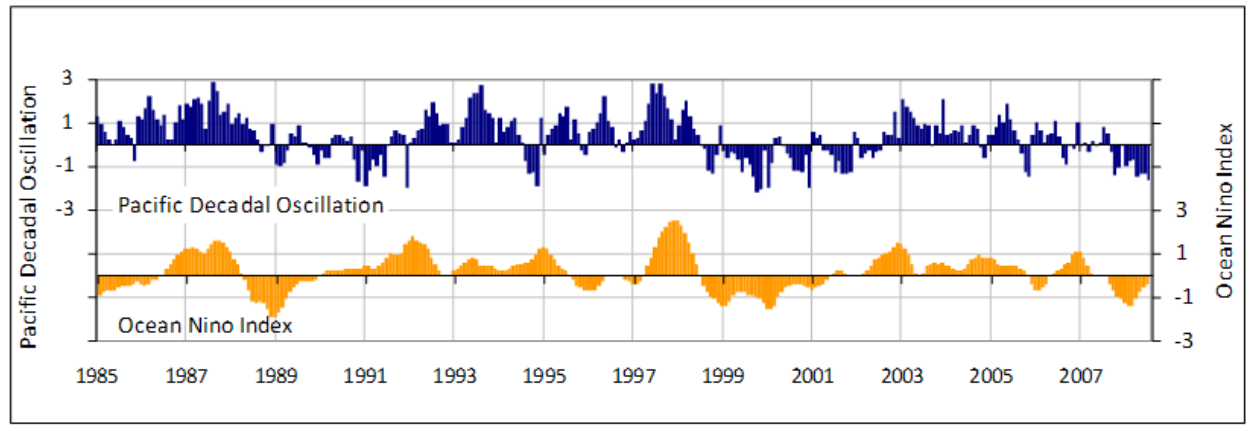

Fig. 6 (A) AVHRR SST anomaly $\left({ }^{\circ} \mathrm{C}\right)$ for the west coast of Vancouver Island, 1985-2008. (B) Pacific Decadal Oscillation and Ocean Nino Indices for the same period.

\section{Arctic Regional Ice Concentrations}

Sea ice is an essential component of the environment in the Arctic with profound effects on the physical oceanography, biological productivity and marine mammal utilization. In recent years, there has been a considerable focus on the sharp decline in sea ice coverage in the present decade for summer with record low values recorded in 2002 and 2005 followed by a further reduction of nearly $25 \%$ in the summer of 2007 [6]. The long-term trend of reduced sea ice coverage amounts to just over $11 \%$ per decade in late summer (Fig. 7). However, Arctic ecosystems are defined and best understood on regional scales rather than over the full North Polar Region. Sea ice in the northern hemisphere exhibit enormous variations among subregions and moreover the interannual variability is larger than the long-term trend for most polar subregions [7].

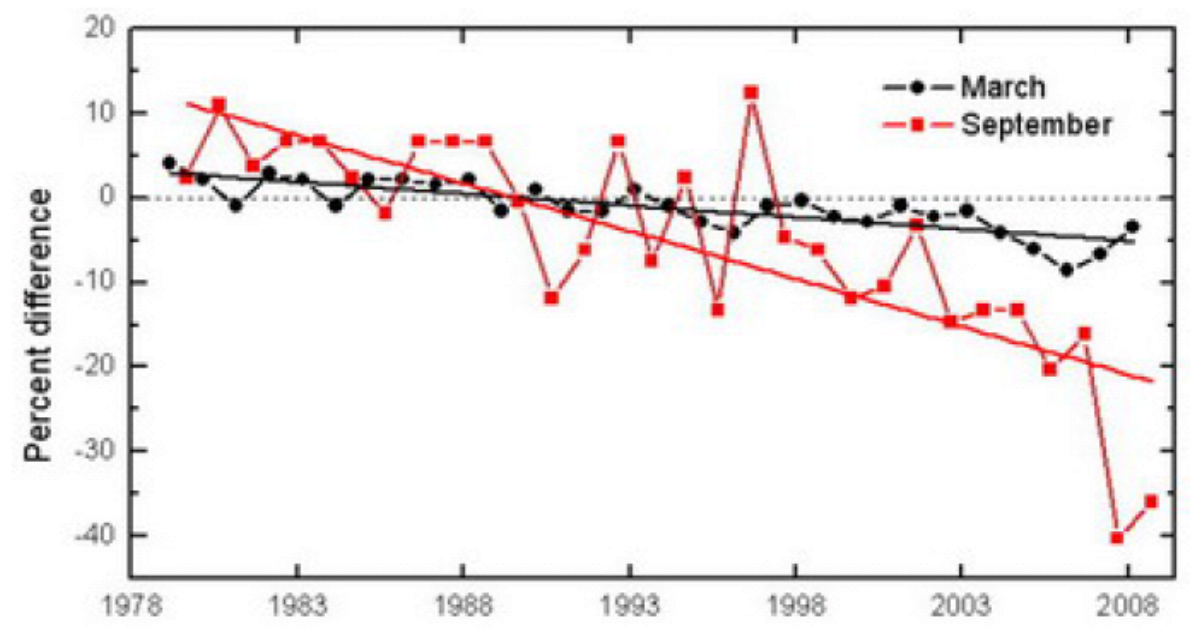

Fig. 7 Time series of the total Northern Hemisphere ice extent in March (the month of ice extent maximum) and September (the month of ice extent minimum) from the mean values for the time period 1979-2007. Based on a least squares linear regression, the rate of decrease for the March and September period was $-\mathbf{2 . 8 \%}$ and $-11.1 \%$ per decade [8]. 
For Northern Hemisphere polar subregions, long-term ice trends and interannual variability has been determined using longterm passive microwave satellite data sets available since 1979 [7]. The passive microwave data sets have the advantage of providing all weather measurement capability; however, the resolution is a rather coarse $25 \mathrm{~km}$ pixel size and the satellite sensors cannot detect the presence of sea ice in concentrations of less than $15 \%$. The coarse resolution limits the capabilities of the passive microwave data sets for coastal regions and also for the confined channels of the Canadian Arctic Islands. An alternative data source for examining change in the Western Arctic marine environment is the digital ice charts prepared and compiled by the Canadian Ice Service (CIS) of Environment Canada [9]. The CIS digital ice charts are available from 1968 to the present at weekly time intervals from June to December with a longer time interval in the winter and spring seasons. These ice charts are derived from multiple data sources that have changed over the past four decades. In the early years, the primary data sources were from visual observations taken by airborne and ship-based ice observers. In the 1970's, multiple satellite data sets became available with resolutions ranging from $100 \mathrm{~m}$ to $15 \mathrm{~km}$. As new and more advanced satellites became available, these data sources were incorporated into the CIS ice chart data product. Since the 1990's to the present, the primary ice chart data source has become the all weather Synthetic Aperture Radar (SAR) satellite, mainly relying on the Canadian Radarsat I satellite launched in 1996, which provide a very high spatial resolution of $25 \mathrm{~m}$. The online CIS ice charts provide multiple ice parameters including total ice concentration as well as partial ice concentrations by ice type and floe sizes which are presented in a GIS digital format with a horizontal resolution of $4 \mathrm{~km}$.

The long-term trends and the interannual variability of sea ice have been computed for sub-regions in the Western Arctic over the past 41 years using the CIS digital ice chart database for selected subregions along the fabled Northwest Passage (Fig. 8) which can be used to develop quantitative measures that may be associated with climate change for local and regional areas.

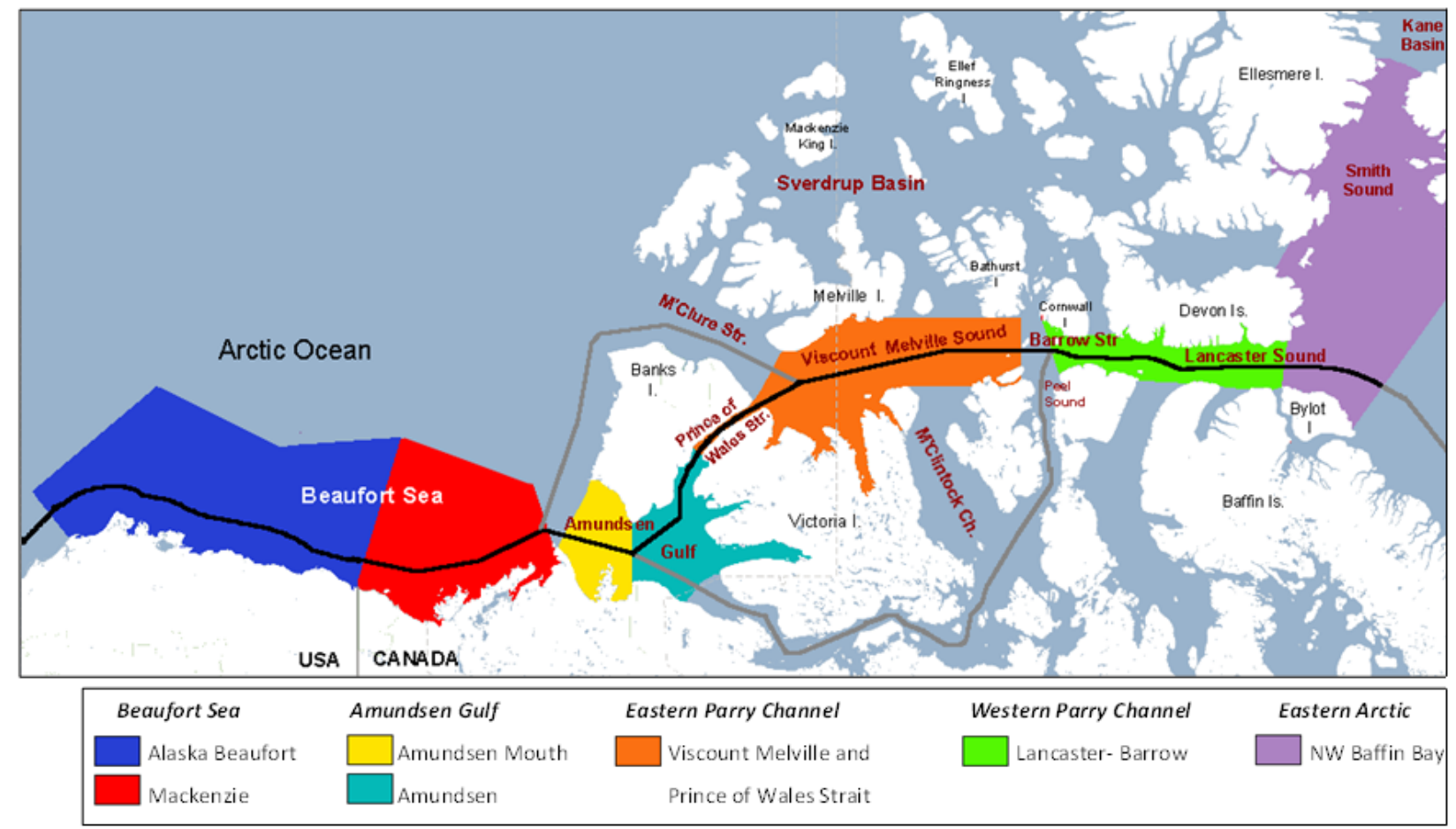

Fig. 8. The subregions for coastal areas and confined channels along the route of the Northwest Passage in the western hemisphere of the Arctic Ocean for which CIS digital ice chart data has been analysed. 


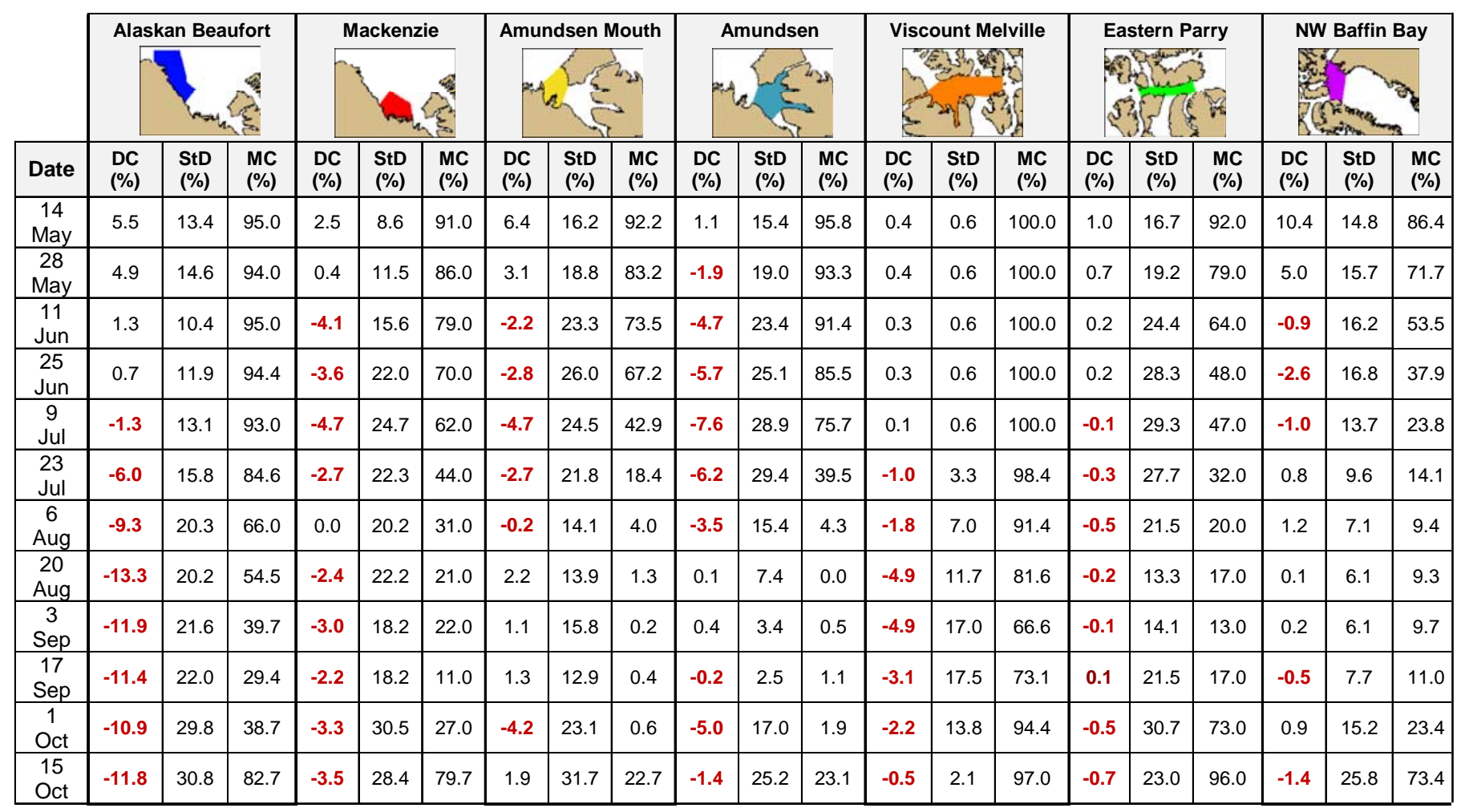

Fig. 9 Summary of regional ice parameters from trend analysis of historical ice coverage for seven subregions of the Western Arctic. Dark red, bold numbers indicate decreasing ice concentrations . DC=1968-2008 Decadal Change $(\%)$ : $\mathrm{StD}=$ standard deviation; MC $=1971-2000 \mathrm{Median}$ Total Sea Ice Coverage (\%).

The large differences within various subregions of the shelf and coastal portions of the western hemisphere of the Arctic Ocean are clearly evident in Fig. 9 with much larger trends occurring in the western subregions by comparison to the central and eastern subregions. Also of interest is the large degree of interannual variability for the various subregions as represented by the standard deviation (StD) values presented in Fig. 9. In many subregions, the total change in ice concentration when computed over the 41 year data record $\left(4.1^{*} \mathrm{DC}\right)$ is less than one standard deviation $(\mathrm{StD})$ as computed over the full record for nearly all the weeks presented. The subregions and times of year when the long-term trend is comparable to or exceeds the standard deviations of total ice concentration is in the late summer for the Alaskan Beaufort Sea, in Amundsen Gulf in early summer and in Viscount Melville Sound in mid-summer. For all other subregions and weekly dates, the long-term trend is considerably less than the change computed over 41 years from the long-term trend. The highly variability by subregion indicates that the changing Arctic ice climate, which is widely believed to be associated with climate change, is occurring in a very uneven manner by subregions and time of year.

\section{CONCLUDING REMARKS}

The increasing availability of satellite data over the past 30 years has vastly improved our understanding of the ocean and remote areas like the Arctic. From the growing time series we are becoming able to resolve spatial and temporal scales of change, to identify anomalous events and their varying local effects as shown in the results presented in this paper. As technology continually improves, we can expect to add to the number of observable parameters along with better measurement for existing parameters in terms of accuracies, resolution and sampling coverage for temporal and spatial scales.

Long-term remote sensing derived data sets coupled with models and in situ observations develop or refine predictive capability in domains as diverse as fisheries, navigation and climate change. Many oceanographic and marine environmental models have been developed in recent years to predict changes related to climate change. The development of these ecosystem models, having application to local and regional study areas will benefit from the use of the satellite-derived data sets in order to calibrate and validate the models over the past few decades which will improve their applicability to predicting future conditions in the coming decades. 


\section{ACKNOWLEDGMENTS}

The Anderson River vegetation study was performed under contract to the Canadian Wildlife Service by Borstad Associates Ltd. Compilation and analysis of the northeast Pacific Ocean SST and chlorophyll datasets was funded by the Canadian Space Agency Earth Observation Government Related Initiatives Program (GRIP), under contract to the Department of Fisheries and Oceans. We also acknowledge the long-term commitment of the Canadian Ice Service of Environment Canada to providing high quality ice data sets over vast areas of the Arctic Ocean and its marginal seas.

\section{REFERENCES}

[1] G.A. Borstad, M.M. de S. Álvarez, J.E. Hines and J.-F. Dufour, "Reduction in vegetation cover at the Anderson River delta, Northwest Territories, identified by Landsat imagery, 1972-2003,” Canadian Wildlife Service Technical Report Series no. 496, 2008.

[2] F. Fetterer and M. Savoie, "Cryospheric climate indicators. Greenness: overview," National Snow and Ice Data Center, http://nsidc.org/noaa/search/indicators/greenness index.html, 2007.

[3] G.J. Jia, H.E. Epstein and D.A. Walker, “Greening of arctic Alaska, 1981-2001,” Geophysical Research Letters vol. 30, p. $2067,2003$.

[4] D.M. Ware and R.E. Thomson, "Bottom-up ecosystem trophic dynamics determine fish production in the northeast Pacific," Science vol. 308, pp. 12801284, May 2005.

[5] R.J. Beamish, R.M. Sweeting, C.M. Neville and K.L. Lange, "Ocean changes in the Strait of Georgia indicate a need to link hatchery programs, fishing strategies and early marine studies of ocean carrying capacity into an ecosystem approach to manage coho salmon," North Pacific Anadromous Fish Commission Technical Report no. 7, pp. 49-51, 2007.

[6] J. Stroeve et al., "Arctic sea ice plummets in 2007.” EOS, Trans. Amer. Geophys. Union, vol. 89, p. 13, 2008.

[7] C.L. Parkinson and D. J. Cavalieri, “Arctic sea ice variability and trends, 1979-2006,” J. Geophys. Res., vol. 113, C07003, doi:10.1029/2007JC004558, 2008.

[8] J. Richter-Menge, J. Comiso, W. Meier, S. Nghiem and D. Perovich, “Arctic Report Card 2008.” Available on-line at http://www.arctic.noaa.gov/reportcard, October 2008.

[9] Canadian Ice Service, “Sea Ice Climatic Atlas - Northern Canadian Waters 1971-2000,” Public Works and Government Services of Canada, ISBN 0-66261973-3, Cat. No. En56-173/2002, 199 p., 2002. 